\title{
LA FUERZA DE LA SANGRE, BEYOND A REASONABLE DOUBT: LA CUESTIÓN DEL DOBLE FINAL
}

En noviembre de 1990, durante el Tercer Coloquio Internacional de la Asociación de Cervantistas, celebrado en Alcalá de Henares, la profesora Ellen Lokos de la universidad de Harvard, USA, en la comunicación titulada Máscaras, mentiras, matrimonio final:-la ejemplaridad de 'La fuerza de la Sangre', proponía a los congregados leer el texto cervantino objeto del estudio a partir de un supuesto doble final del mismo, o mejor, en sus propios términos, teniendo en cuenta la existencia de un final textual basado en elementos objetivos: la conclusión material del relato; frente a una clausura efectiva, basada en elementos de carácter esencialmente críticos, que apelarían, en última instancia, a la coherencia interna de este. De modo que el final objetivo de La Fuerza de la Sangre lo constituiría la feliz y prolífica descendencia anunciada, en tanto que la clausura o verdadero final del relato, en contra de ese final considerado postizo e impuesto por condiciones ajenas al mismo, lo constituiría el silencio de sepultura que sigue a la inesperada resolución del conflicto planteado

Llegóse, en fin, la hora deseada, porque no hay fin que no le tenga. Fueronse a acostar todos, quedo toda la casa sepultada en silencio...

Verdadero final que, según Ellen Lokos, multiplica la naturaleza ejemplarizadora de lo narrado: el hundimiento irremediable de la condición femenina en el silencio humillante del hogar patriarcal.

Mi intención en este breve escrito es mostrar como no es preciso apelar a tales extremos para establecer la naturaleza ejemplar de la novela cervantina, ni aun su interpretación subversiva de la realidad. Para lo cual enfrentaré (en un verdadero tirabuzón crítico) el texto cervantino con otro de carácter bien distinto y lejano en el tiempo: el film realizado en 1956 por el director de cine vienés Fritz Lang (1890-1976), titulado Beyond a Reasonable Doubt; precisamente el último y uno de los más representativos de su prolongada etapa americana.

Si el nervio argumental de la tesis sostenida por la profesora Ellen Lokos se basa en que la conclusión de un relato, cualquiera que éste sea, puede ser percibida bien como un final impuesto por cierta presión externa; esto es, por un conjunto de circunstancias sociales, políticas o culturales ajenas al texto; o bien como un final específico, basado en la coherencia interior del relato, ese conjunto de leyes e intuiciones inmanentes que operan en un texto 
dotándolo de cohesión e identidad; nada más adecuado para ayudarnos a comprender esto que el análisis de un film que se entronca indefectiblemente en la tradición del doble final, tan característica del cine de Hollywood a partir de los años cincuenta, en pleno McCarthysmo.

Además, la figura de Fritz Lang, un hijo del viejo Imperio Austro-húngaro en el Hollywood del star system, no deja de recordarnos por su anomalia, al Cervantes aventurero y humanista rezagado en el corazón de la Contrarreforma. Pero, sobre todo, es ese idealismo pesimista y romántico que contempla cómo el hombre se debate con un destino personal y pierde inevitablemente ${ }^{1}$, fundamento del universo cinematográfico de Lang, lo que hace más sugerente, si cabe, el encuentro entre ambos creadores.

El argumento de la novela cervantina es conocido por todos, una doncella, violada una noche de verano, tras una peripecia marcada por lo azaroso, al cabo de siete años, descubre y finalmente se casa con su agresor, joven impetuoso y crápula de noble cuna toledana.

El film de Lang trata de la pena de muerte, al menos aparentemente. Garrett, un novelista a punto de casarse con Susan, hija de un famoso editor de un diario liberal que cuestiona públicamente el poder absoluto del Estado para imponer la pena máxima, la muerte legal; se ve implicado en una azarosa trama, urdida por el padre de la novia con el fin de desenmarcar la injusticia radical de la muerte de un inocente a partir de la acumulación casual de pruebas circunstanciales. Cuando finalmente es acusado y condenado a muerte por un crimen que, estamos convencidos, él no ha cometido, Austin Spencer, padre de Susan e inductor de la trama, es atropellado por un automóvil y las pruebas exculpatorias de Garrett se pierden irremediablemente; un inocente va a ser ajusticiado por un error de la Justicia misma. Todo parece encajar con la tesis inicialmente propuesta: el horror y la brutalidad de la muerte legal; sin embargo, en una cabriola final del argumento, Garrett se descubre como verdadero asesino de la corista Patty, en realidad, la mujer legal de Garret, que impide a éste su matrimonio con Susan.

Esta imprevista especie de justicia poética se consuma irónicamente cuando Susan, a pesar de que los documentos exculpatorios de Garrett han sido casualmente hallados y el Gobernador está a punto de firmar la libertad del novelista, decide la condena de su novio denunciándolo como verdadero asesino, aunque ello signifique su muerte y la afirmación de todos aquellos valores que su padre y ella misma, después de su trágico accidente, han combatido desde el periódico.

Según Ellen Lokos, las condiciones externas que debieron influir en esa especie de happy end con el que concluye la novelita de Cervantes, estarían relacionadas con el control ideológico establecido por la cultura inquisitorial de la Contrarreforma, tanto como con la dependencia económica y la inestabilidad social del autor, sometido a los caprichos del mecenazgo.

1 Andrew Sarris, en Film Culthue, n 28. 1963. 
Del mismo modo, habría que pensar que el inesperado giro del film de Fritz Lang guarda estrecha relación con el código Hays, con la cultura inquisitorial impuesta por el McCarthysmo, y con las condiciones de la industria y la producción cinematográfica del Hollywood de aquellos años, en que el director no es más que un asalariado al que no se le reconoce la propiedad intelectual de la obra realizada, sujeto siempre a las presiones de guionistas y de productores.

Pero existe otra posibilidad, que la conclusión de ambos textos se ajuste a una coherencia interna imprevista y paradójica.

Interpelado por Peter Bogdanovich, contesta Fritz Lang ${ }^{2}$ (Dana Andrews es Garrett; Joan Fontaine es Susan)

'Tenía mucho miedo del final. Mostraba a Dana Andrews durante una hora y cuarenta minutos como un hombre limpio y maravilloso, y en dos minutos muestro que es un hijo de perra. Estaba muy asustado.

¿No era la traición de Joan Fontaine en ese momento mucho más reprobable que cualquier cosa que habia hecho Andrews?

De nuevo, podría hablar de esto durante mucho tiempo. Olvidemos su carácter por un momento - creo que tiene razón usted al pensar asi -, pero supongamos que es una chica dulce, maravillosa y comprensiva, y que de pronto descubre que el hombre al que ama es el mayor hijo de perrra. ¿no le abandonaría?

Abandonarle es una cosa, traicionarle es orra.

¿Quiere que ella se convierta en su cómplice? ¿Que luego él vaya y mate otra vez? Como dije, podríamos hablar mucho sobre esto.

Sin embargo, en la película, usted la había presentado como el tipo de persona que haría lo que hizo, y aun asi resultaba terrible.

Acaba usted de decir: 'Usted la presentó'. Exacto. Esta es, otra vez, la misión del director. Tenía que hacerlo, o todo se desmorona al final. Pero ella no es más que un ser humano; es un ser humano igual que las personas que a usted no le gustan de While the City Sleeps.

¿Diria usted que ella era un retrato de la mujer puritana americana?

Peter Bogdanovich, Fritz Lang en America, Madrid, Editorial Fundamentos, 1972., pp. $96,97$. 
Yo sólo he tenido muy buenas experiencias con mujeres americanas. No sé que experiencia habrá tenido usted... Era un tipo de mujer.

\section{¿Tuvo problemas con el productor de este film?}

Tuve una pelea infernal con él acerca de las escenas de las celdas de los condenados. Vino y me dijo: 'Fritz, hazlas muy reales'. Le dije: 'Tendrás problemas con la Oficina Central o con los distribuidores ante los que eres responsable'. Dijo: 'No'. Entonces uno de esos típicos pequeños espías - que están siempre en el estudio cuando uno está rodando - fue a la Oficina Central, y el productor fue convocado ante ellos. Volvió echando humo y me dijo: 'iHijo de perra, no está ya en la Ufa! ¿Por qué estás rodando escenas tan crueles?' No fue mi primera pelea. Tuve otras peleas con él. Estaba asqueado. Le dije a mi montador, Gene Fowler, lo que quería, para saber que la película estaría en buenas manos, y me fui. Entonces, cuando todo estaba terminado, el productor empezó de pronto a estar amable otra vez: 'Pero no querrás dejarme ahora, ¿no?' Le dije: 'Sí, estoy asqueado y harto de ti'. Me fui. Reconsideré el pasado - cuántas películas habían sido mutiladas -, y como no tenía la menor intención de morir de un ataque cardíaco, dije: 'Creo que dejaré esta carrera de ratas'. Y decidí no hacer películas aquí nunca más."

¿Qué acción, pues, resulta más condenable, la fría decisión de Susan o el asesinato de Patty? Pero, lo que es más importante, en medio de esa tensión constante y agobiante entre el creador y su medio, ¿cuál ha sido la verdadera intención del autor? ¿cuál, su posición frente a lo narrado?

En La fuerza de la Sangre, Leocadia y Estefanía, la madre del agresor, han puesto en pie una calculada estrategia, cuyo fin es precisamente el matrimonio. Como ha señalado Harry Sieber ${ }^{3}$, la felicidad conyugal de los amantes viene a ser, en última instancia, el azaroso fruto de la violencia y del engaño. Otras interpretaciones, por lo contrario, ven en el desarrollo y conclusión del relato cervantino un todo discursivo encaminado bien a la exaltación de la familia cristiana ${ }^{4}$, bien a la representación del tránsito místico del pecado a la redención ${ }^{5}$. Sea como fuere, el aspecto más interesante de la tesis sostenida por la profesora norteamericana, aquel que identifica a Leocadia con la fuerza de la alocución y a Rodolfo con la brutalidad de la violencia elemental, muestra una nueva vertiente aleccionadora, si se considera el final del relato como el postrer triunfo de la primera sobre la segunda. ¿No es tal vez una sutil y corrosiva paradoja que el honor del agresor sea

3 Harry Sieber, edición de Las Novelas Ejemplares, Madrid, Cátedra, 1990.

4 Nina M. Scott, "Honor and Family in La filerza de la sangre" en Estudios de Hispanifila, 46, 1977, pp. 125- 132.

5 Joaquín Casalduero, Sentido y Fonna de las Novelas Ejemplares, Madrid, Gredos, 1974. 
finalmente rehabilitado por la capacidad razonadora de su víctima? ¿Hay, además, alguna otra probabilidad, aparte de la prostitución o del monacato, que garantice una relativa emancipación a las mujeres del siglo XVII?

Ahora bien, si la profesora Lokos ha propuesto una lectura de la novela a partir de un supuesto doble final, es porque ello puede ser, hasta cierto punto, justificado con datos procedentes del propio texto, aunque sus conclusiones no aumenten, como se pretende, la naturaleza ejemplar del mismo; puesto que tal naturaleza deviene no de la tesis sostenida explícita o tangencialmente por el autor, sino, como sostiene Riley ${ }^{6}$, del ensanchamiento del horizonte estético y literario promovido por Cervantes al integrar la perspectiva del lector y su consiguiente libertad de interpretación en la obra literaria.

Es esta inapreciable aportación de Cervantes a la novela y al arte contemporáneo, en general, la que sirve de fundamento estético a la obra de Fritz Lang y a gran parte de la literatura moderna, dotándola de una potencialidad interpretativa abierta y multivalente. Lo ejemplar, por tanto, es un concepto cervantino de carácter esencialmente estético, que resulta finalmente ético al afirmar la libertad individual de interpretación de la realidad.

Para concluir, señalaremos como en ambos textos se proponen una serie de indicios que anuncian el final paradójico de los mismos.

Con respecto al film de Lang, destacaría tres: el diseño del personaje de Susan, que, como señala Bogdanovich, al denunciar a su prometido parece satisfacer uno más de sus exigentes caprichos; aquellos de los que habla, al comienzo de la película, su padre, cuando previene a Garrett. En segundo lugar, el hecho mismo de que este, a punto de casarse, acepte la arriesgada puesta en escena, con lo que el tono del film queda inmediatamente establecido. Y, por último, un detalle argumental aparentemente trivial, la mancha de tabaco en la caja de cerillas hallada en el lugar del crimen.

Así, pues, ¿cuál es el verdadero tema de Beyond a Reasonable Doubt, la pena de muerte $\mathrm{o}$, como en otros tantos films de Lang, recordemos los bellos y patéticos ejemplos de Rancho Notorius (1952) o You Only Live Once (1937), la azarosa derrota del individuo, incapaz de modificar su fatal destino?

En cuanto a la novela de Cervantes, Leocadia acepta incondicionalmente el código de la honra entendida como opinión pública y, en consecuencia, establece toda una estrategia de ocultamiento y, una vez favorecida por el azar-providencia, de reintegración, cuyo solo objetivo es el matrimonio

viendo también tan cerca de sí al que ya quería más que a la luz de sus ojos..., comenzo /Leocadia/ a revolver en su imaginación lo que con

Edward C. Riley, Teoria de la Novela en Cervantes, Madrid, Taurus, 1966. 


\section{Rodolfo habia pasado. Comenzaron a enflaquecerse en su alma las}

esperanzas que de ser su esposo su madre le habta dado...

Además, han transcurrido siete años, y algo extraordinario debe suceder. El carácter ambivalente de la conclusión del relato tiene más que ver, así, con ciertos objetivos que definen la Poética cervantina: con la explícita propuesta de un texto abierto y ejemplar que no excluya la actividad interpretativa del lector; con el reto de hacer verosímil un desatino; o con la aplicación sistemática de estructuras narrativas basadas en la antítesis simétrica, la oscuridad silenciosa del orden restablecido ${ }^{7}$; que la toma de posición específica de Cervantes respecto a la condición femenina y la inevitable presión del medio cultural y político.

No obstante, Cervantes y Fritz Lang enuncian artísticamente, con ironía y cierta tristeza, las condiciones totalitaristas que emanan de los otros individuos, del destino, y de la colectividad social, entendida como suma de valores sobre los que se asienta el Estado, y que entretejen irremediablemente nuestra derrota.

\section{Povzetek}

\section{MOČ KRVI, BEYOND A REASONABLE DOUBT: PROBLEM DVOJNEGA KONCA}

Harvardska profesorica Ellen Lokos je na kongresu cervantistov leta 1990 razvila tezo o dvojnem koncu kakršnekoli pripovedi: o koncu, ki ga bralcu vsiljuje zunanje okolje, v katerem je besedilo nastalo (družbene, politične ali kulturne okoliščne) in o specifičnem, literarnokritǐ̌nem koncu, ki temelji na notranjem ustroju besedila. Kot primer navaja znano Cervantesovo vzorno novelo La Fuerza de la Sangre (Moč krvi), ki je nastala v času inkvizicijske kulture, usmerjene proti reformaciji.

Avtor prispevka polemizira $\mathrm{z}$ omenjeno tezo in navaja kot primer film Fritza Langa Beyond a Reasonable Doubt, posnetega v avtorjevem hollywoodskem obdobju in v času McCarthyjeve gonje, ki se kot totalitarni čas lahko primerja s Cervantesovim. Zakjjučuje, da gre $\mathrm{v}$ obeh primerih za odprti besedili, ki problematiko dvojnega konca $\mathrm{v}$ interpretaciji dolgujeta bolj avtorjevi poetiki in jasnovidnosti kot zunanjim okoliščnam.

7 Robert V. Piluso, "La Fuerza de la Sangre: un análisis estructural", en Hispania, 47, 1964, pp. 485-490. 